\title{
KESULITAN-KESULITAN SISWA DALAM BELAJAR SPEAKING ENGLISH
}

\section{A'AM RIFALDI KHUNAIFI \\ Dosen Fakultas Keguruan Dan IImu Pendidikan Universitas Muhammadiyah Palangkaraya}

\section{ABSTRAK}

Penelitian ini bertujuan untuk menjawab permasalahan mengenai kesulitan-kesulitan yang dialami oleh siswa dalam belajar speaking English di Sekolah MAN Model Palangka Raya Kelas

Metode penelitian yang digunakan dalam peneltian ini adalah Analitycal Research yaitu mengambil langkah deskriptif penggabungan antara metode kualitatif dengan metode kuantitatif. Populasi penelitian ini adalah siswa kelas XI.I.S-1 dan XI.I.S-2 di MAN Model Palangka Raya yang berjumlah 65 siswa. Pengambilan sampel, peneliti menggunakan Purposive Sampling dan menggunakan homogenous sample yang diambil dari salah satu enam tipe-tipe Purposive Sampling. Adapun metode pengumpulan data yang digunakan adalah observasi, interview, tes dan dokumentasi.

Hasil penelitian ini menunjukkan bahwa kesulitan-kesulitan yang dhadapi siswa MAN Model palangka raya kelas xi.i.s ini meliputi : pola interaksinya masih bersifat sederhana hal ini dibuktikan dari hasil tes tanpa score, karena pola yang digunakan siswa untuk presentasi homogen dan sederhana.

\section{Kata Kunci : Belajar dan Speaking English}

\section{PENDAHULUAN}

Speaking adalah alat penting untuk berkomunikasi, berpikir, dan belajar. Bahasa lisan adalah alat belajar yang kuat. Ini membentuk. Memodifikasi, meluas. Dan mengatur pikir. Bahasa lisan adalah dasar dari semua perkembangan bahasa dan oleh karena itu, dasar dari semua pembelajaran. Ini adalah dasar untuk tiap bahasa lain. Melalui Speaking dan belajar, siswa dapat belajar konsep, mengembangkan kosa kata dan memahami struktur.

Berbicara merupakan salah satu keterampilan produktif dalam mode lisan. Ini, seperti keterampilan lain, lebih rumit dan tampaknya akan melibatkan lebih dari sekedar mengucapkan kata dengan menyatakan bahwa dan interaksi (Speaking) secara konvensional dalam menyajikan informasi yang dapat difokuskan sebuah informasi dan interaksi. Bahasa Inggris dianggap sebagai yang pertama dalam bahasa asing internasional yang resmi diajarkan mulai dari SD, SMP hingga tingkat universitas. Belajar bahasa Inggris adalah suatu keharusan bagi para siswa karena bahasa Inggris memiliki fungsi penting di Indonesia. Selain untuk digunakan sebagai suatu komunikasi internasional, Bahasa Inggris juga dibutuhkan untuk mendapatkan ilmu pengetahuan, teknologi, posisi pekerjaan, promosi dan bahkan waktu ini adalah banyak menawarkan beasiswa untuk luar negeri. Oleh karena itu, kita harus menguasai bahasa Inggris.

Bahasa Inggris tidak hanya merepresentasikan bahasa internasional, tetapi juga dengan bahasa ini kita dapat membangun hubungan yang baik menutup antara negaranegara negara dan kita dapat menyaring budaya eksternal ke dalam Negara kita. Oleh karena itu Presiden dari Republik Indonesia dalam keputusan termasuk dalam Laws dari Republik Of Indonesia dari nomor 2 tahun 1989 tentang sistem dari pendidikan nasional mengatakan: "Untuk mewujudkan pembangunan nasional dalam pendidikan sangat dibutuhkan oleh make-up dari 
kualitas dan penyelesaian pendidikan Nasional".

\section{METODE PENELITIAN}

Peneliti sebagai salah satu usaha memcahkan masalah secara ilmiah memerlukan metode-metode atai cara-cara tertentu untuk melakukan peneltiandisebut metode penelitian. Metode yang di gunakan dalam menjawab permasalahan ini adalah Analytical research. Penelitian analitik ini membutuhkan penelitian deskriptif satu tahap lebih jauh dengan berusaha menjelaskan alasan di balik kejadian tertentu dengan menemukan hubungan kausal. Setelah hubungan kausal telah ditemukan, pencarian kemudian bergeser ke faktor-faktor yang dapat diubah (variabel) untuk mempengaruhi rantai kausalitas. Penelitian Analytical research ini bisa bersifat kuantitatif atau kualitatif tergantung pada apakah permasalahannya.

Penelitian ini merupakan penelitian naturalistik untuk menggambarkan fenomena nyata yang sesuai dengan fakta di lapangan tentang Belajar Berbicara Bahasa Inggris.

According to Znaniecki in Branen states that Analitycal research is the research looks for simmilar caracteristic and put it into abstrac because of it's gnerelazation. If that must be esence of speacial case. The last is drawn abstraction from the case concrete that there are esence and generelazation, as long as it is esential these characteristics are simmilar in many cases.

Dalam rangka untuk mengambil Subyek penelitian penulis menggunakan purposive sampling. menurut Darrel N. Caulley, purposive sampling digunakan sebagai strategi ketika salah satu ingin untuk memahami sesuatu tentang kasus tertentu tanpa menggeneralisasi semua kasus tersebut. Bahkan mungkin akan dipertanyakan cuaca generalisasi ini dimungkinkan karena terdapat perbedaan yang besar antara kasus ofte, terutama jika kontekstualitas kasus juga bervariasi. Pada MAN Model Palangka Raya. Para siswa yang menjadi subjek, diambil dengan menggunakan sampel homogen.

Menggunakan teknik yang bertujuan untuk menggambarkan beberapa khusus subkelompok secara mendalam. Dalam hal ini bagi siswa yang mengalami kesulitan dalam belajar berbahasa Inggris. Total mahasiswa tahun kedua kelas IPS di MAN Model Palangka Raya dapat dilihat sebagai berikut:

The Students Of XI.I.S-1 and XI.I.S-2 At MAN Model Palangka Raya

\begin{tabular}{|c|c|c|c|c|}
\hline No & Classes & Male & Female & Total \\
\hline 1. & IPS - ${ }^{X I}$ & 20 & 12 & 32 \\
\hline 2. & IPS -2 & 18 & 14 & 32 \\
\hline . & TOTAL & 38 & 26 & 64 \\
\hline
\end{tabular}

Ada empat teknik untuk menentukan dukungan dari data, yaitu kredibilitas, transferabilitas, dan konfirmabilitas dependebility.

\section{a. Credibility}

Dalam penelitian kualitatif, untuk data dapat dipercaya dan memenuhi hal kredibilitas, data harus diakui dan diterima oleh trully sumber informasi penelitian. Untuk efford agar kebenaran penelitian ini diyakini, hal ini didukung oleh beberapa hal, sebagai berikut:

\section{The existence of participation}

2. Do Observation diligently

\section{Tringulation}




\section{Member Check}

\section{b. Transferability}

Transferabilitas berkaitan dengan pertanyaan, seberapa jauh hasil penelitian dapat diterapkan oleh orang lain dalam konteks lain. Jadi, penulis harus membuat laporan yang menjelaskan dengan jelas tentang berbahasa Inggris ke speaker dapat mudah memahami hasil penelitian.

\section{c. Dependability}

Keteguhan dilakukan dengan audit semua proses penelitian untuk membuktikan data yang dapat diandalkan. Jadi, penulis harus fokus untuk masalah ini, ke lapangan, menentukan sumber data, melakukan analisis data, memeriksa dukungan data dan membuat kesimpulan dari data.

\section{d. Confirmability}

Konfirmabilitas ini dicapai dengan meminta penasihat atau ahli untuk memeriksa proses penelitian yang berhubungan dengan proses yang dilakukan. Artinya, hasil dan proses harus seimbang. Berdasarkan menjelaskan di atas, Ini bisa menjadi sketsa dukungan Data:

\section{HASIL DAN PEMBAHASAN}

Based on the result of the interview, the problem faced the students in preparing to learn speaking before the class as follows :

\begin{tabular}{|l|l|l|}
\hline No & \multicolumn{1}{|c|}{ Problems } & \multicolumn{1}{|c|}{ Explanation } \\
\hline 1. & $\begin{array}{l}\text { The students' effort to handle the } \\
\text { difficulties }\end{array}$ & $\begin{array}{l}\text { They Read dictionary and look for in Internet, } \\
\text { pray to Allah, they request from family and } \\
\text { ask the teacher. In the home they study with } \\
\text { brother and sister }\end{array}$ \\
\hline 2. & Problem from the students & $\begin{array}{l}\text { The difference of Indonesia language, English } \\
\text { language and difficulties in speaking }\end{array}$ \\
\hline 3. & Support for environment & $\begin{array}{l}\text { They parent's give a dictionary, support to } \\
\text { learn diligent and the students will is } \\
\text { Pilgrimage and didn't have support from they } \\
\text { parents. }\end{array}$ \\
\hline 4. & $\begin{array}{l}\text { When the students have the } \\
\text { problem }\end{array}$ & $\begin{array}{l}\text { They Read dictionary and look for in Internet, } \\
\text { pray to Allah, they request from family and } \\
\text { ask the teacher }\end{array}$ \\
\hline 5. & Finding ideas & $\begin{array}{l}\text { They hard to find idea related to the topic. } \\
\text { Exm :- Stick Tempe }\end{array}$ \\
\hline 6. & Vocabulary & shoot, fruit, steak mean cow \\
\hline 7. & Sentence & Two egg, fried steak tempe until brown \\
\hline
\end{tabular}


Berdasarkan hasil penelitian dapat diketahui bahwa Berdasarkan tabel dan grafik di bawah ini, dapat dilihat bahwa untuk Open Presentation, sebagian besar siswa $31,25 \%$ mengatakan (c), siswa $14,58 \%$ kedua berkata (d), siswa $8,33 \%$ ketiga mengatakan (a \& k ), siswa sebagainya $6,25 \%$ mengatakan ( $f \& n$ ), siswa kelima $4.17 \%$ mengatakan (b, e dan I), siswa keenam 2,08\% mengatakan ( $\mathrm{g}, \mathrm{h}, \mathrm{i}, \mathrm{j}, \mathrm{m}$ dan o).

Data ini mengatakan bahwa siswa cenderung menggunakan ekspresi sehari-hari yang mereka pelajari di gunakan untuk tindakan.

\section{In order to ask repetition in a presentation you can say?}

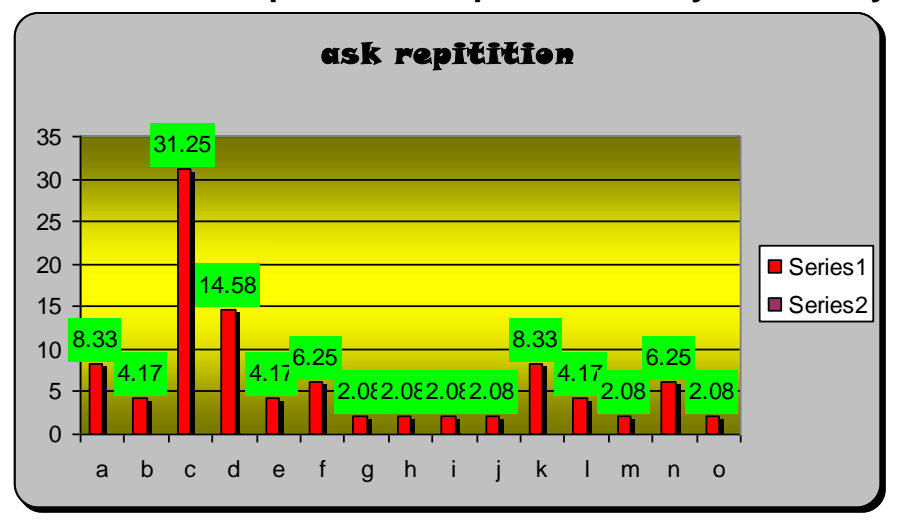

Hasil presentasi siswa di depan kelas

\begin{tabular}{|c||l|c|c||}
\hline No & \multicolumn{1}{|c|}{ Patterns of Interaction } & $\begin{array}{c}\text { Groups } \\
\text { Presentation }\end{array}$ & $\%$ \\
\hline \hline 1. & The Students' presentation to audience & 7 & 63.636 \\
\hline \hline 2. & From Presenter \& from audience & 0 & 0 \\
\hline \hline 3 & Question From audience to the presenter & 5 & 45.454 \\
\hline \hline \multicolumn{2}{|r|}{ SUM } & 12 & $100 \%$ \\
\hline
\end{tabular}

Based on the table above, at concludes that there is group sevens (7) that classes ahead presentation and there's only four (4) group that get

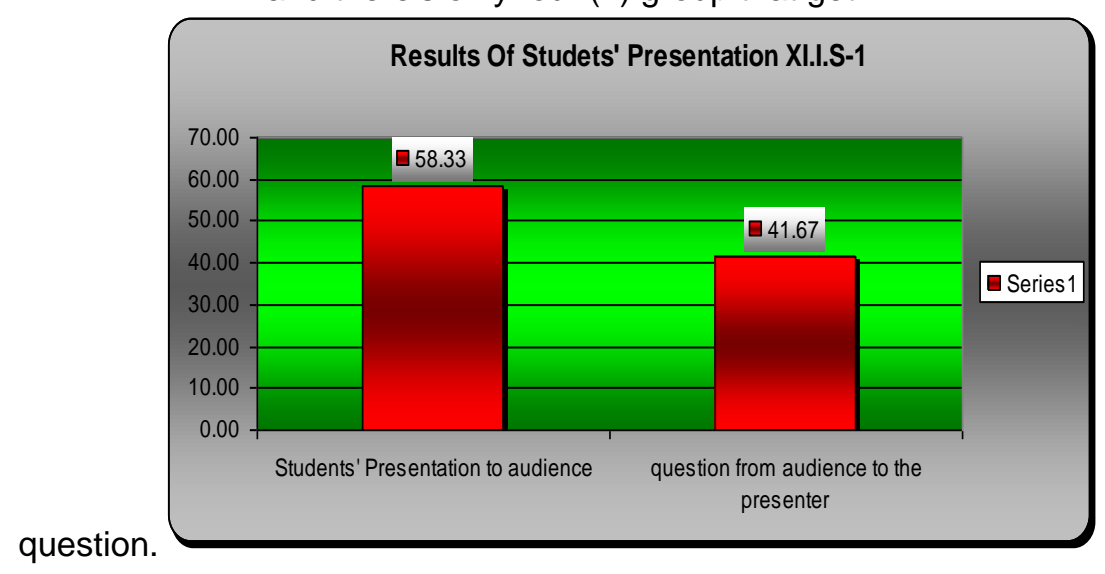




\section{KESIMPULAN DAN SARAN}

\section{Kesimpulan}

Berdasarkan hasil analisis yang diperoleh dalam pelaksanaan kegiatan penelitian tentang kesulitan-kesulitan siswa dalam belajar speaking English, maka dapat disimpulkan sebagai berikut :

1. Masalah yang dihadapi oleh para siswa dalam persiapan untuk Speaking English
a. kosakata
b. frase atau kalimat gramatikal
c. ide

2. Masalah yang dihadapi oleh siswa dalam in learning speaking English
a. Mereka banyak waktu untuk menjawab dan mengajukan pertanyaan.
b. Kosakata dan tata bahasa kekurangan

3. Masalah yang dihadapi oleh siswa dalam pengulangan item pelajaran setelah belajar berbahasa Inggris,.
a. Inggris dan Indonesia berbeda
b. Mereka tidak suka bahasa Inggris

Masalah masih ada meskipun guru yang sangat berpengalaman dan siap dalam mengajar.

\section{Saran}

\section{Saran untuk Siswa diharapkan:}

1. Siswa harus berkonsentrasi dengan baik dalam mendengarkan untuk mengikuti kegiatan berbicara.

2. Siswa harus membangun hubungan dengan kapal lain, di luar

3. Siswa harus sering pergi kunjungan ke perpustakaan untuk membaca atau meminjam buku yang akan bantalan dengan bahasa Inggris atau yang lain yang menambah pengetahuan.
4. Mahasiswa perlu belajar kelompok untuk dapat berkomunikasi satu sama lain saling jika cacat tersedia di pelajari.

5. Situasi belajar mahasiswa ruangan harus diatur dalam kondisi tertentu untuk

6. Setiap siswa yang sekolahnya lengkap sebagai bahan seperti membaca utilisedding untuk menambah beasiswa yaitu gotten di sekolah.

\section{Saran untuk orang tua}

Belajar untuk meningkatkan prestasi siswa akan berhasil jika mendapat dukungan dari orang tua, terutama dalam melakukan aktivitas belajar di rumah. Perhatian orangtua di rumah pada anak-anak itu berupa belajar, memberikan teguran jika standar anak-anak dalam belajar, dan pada kejadian yang memberikan ruang dan waktu untuk studi anakanak di rumah sebagai penting artinya bagi upaya untuk mempelajari peningkatan siswa sikap disiplin itu. Untuk itu disarankan agar para orang tua tidak keberatan berkonsultasi dengan guru jika menemukan masalah.

\section{DAFTAR PUSTAKA}

Julia Brannen. 1997, Memadu Metode Penellitian kualitatif dan Kuantitatif, Yogyakarta, Pustaka Pelajar, pg 14

Bimo walgito, 1989.Undang-undang Republik Indonesia nomor 2 tahun 1989 tentang sistem Pendidikan Nasional.Jakarta : percetakan Negara.

Julia Brannen. 1997, Memadu Metode Penellitian kualitatif dan Kuantitatif, Yogyakarta, Pustaka Pelajar, pg 14

Mudjia Rahardjo, Pengantar Penelitian Bahasa, Malang:Cendekia Para Mulya,2002, pg. 56 
Suharsimi Arikunto, Prosedur Penelitian, Jakarta: Rineka Cipta, 1993, p. 197

Moleong Lexy,J.(1987), Metodologi Pendidikan Kualitatif. Bandung Remaja Rosda Karya 